\title{
Estimação do valor energético da pastagem e simulação de parâmetros do desempenho produtivo de novilhas em pasto
}

[Estimation of pasture energy value and simulation of productive performance of heifers under grazing]

\author{
F.N. Lista ${ }^{1}$, J.F.C. Silva ${ }^{2 *}$, E. Detmann ${ }^{3}$, H.M. Vasquez ${ }^{2}$, P.A.M. Malafaia ${ }^{4}$ \\ ${ }^{1}$ Aluno de pós-graduação -UENF - Campos, RJ \\ ${ }^{2}$ Universidade Estadual Norte Fluminense \\ Av. Alberto Lamego, 2000 \\ 28013-602 - Campos dos Goytacazes, RJ \\ ${ }^{3}$ Universidade Federal de Viçosa - Viçosa, MG \\ ${ }^{4}$ Universidade Federal Rural do Rio de Janeiro - Seropédica, RJ
}

\begin{abstract}
RESUMO
Estimaram-se o valor energético das forrageiras e o consumo de matéria seca por novilhas, em função do ganho de peso, criadas em pastagens de capim-elefante (Pennisetum purpureum Schum. cv. Napier) e capim-mombaça (Panicum maximum, cv. Mombaça), manejadas sob sistema rotacionado, mediante amostras tomadas via extrusa esofágica. As amostras relativas ao terceiro, segundo e primeiro dias de ocupação foram utilizadas para determinar os teores matéria seca, proteína bruta, extrato etéreo, fibra em detergente neutro, fibra em detergente ácido, lignina e cinzas para calcular os nutrientes digestíveis totais (NDT). Os valores do NDT preditos pelo sistema americano (NRC) e os estimados a partir do ganho de peso foram comparados com ajustamento de modelo de regressão linear simples. Os ganhos médios de peso diário foram de $0,649 \mathrm{~kg}$ e de $0,590 \mathrm{~kg}$, respectivamente, para o capim-elefante e para o capimmombaça, o que resultou na rejeição da hipótese de nulidade, ou seja, resultou em ausência de equivalência entre os valores preditos pelo sistema e os observados. A incorporação do fator empírico de correção $(0,85)$ em substituição ao valor $(0,667)$ proposto pelo NRC minimizou a ocorrência deste comportamento viesado.
\end{abstract}

Palavras-chave: pastagem, nutrientes digestíveis totais, sistema americano, ganho de peso

\begin{abstract}
Elephantgrass (Pennisetum purpureum, Schum. cv. Napier) and mombaçagrass (Panicum maximum, cv. Mombaça) pastures were evaluated under rotational grazing with samplings taken by esophageal extrusa. The energy value of grasses and the dry matter intake of heifers as a function of the weight gains were estimated. Samples relating to the third, second, and first days of the occupation period were used to determine the dry matter (DM), crude protein (CP), ether extract (EE), organic matter (OM), neutral detergent fiber (NDF), and acid detergent fiber (ADF) to calculate the total digestible nutrients (TDN). The TDN values predicted by the American System (NRC) and those estimated from heifers weight gains were compared with adjustment of simple linear regression. The average weight gains were 0.649 and $0.590 \mathrm{~kg}$, respectively, for elephantgrass and mombaçagrass, that resulted in the rejection of nullity hypothesis, which means, it resulted in absence of similarity among values predicted by the system and those observed. The incorporation of the empirical factor (0.85) replacing the value (0.667) proposed by $N R C$ resulted in better estimation.
\end{abstract}

Keywords: pasture, total digestible nutrients, American System, weight gains

Recebido em 4 de setembro de 2007

Aceito em 31 de janeiro de 2008

*Autor para correspondência (corresponding author)

E-mail: jcoelho@uenf.br

Apoio: CNPq e FAPERJ 


\section{INTRODUÇÃO}

Um dos principais componentes do sistema de produção na pecuária é a alimentação, em especial à relacionada às pastagens. Nesse caso, os pecuaristas precisam planejar sistemas de exploração cada vez mais lucrativos. Assim, o conhecimento das características das forrageiras é essencial para estabelecer procedimentos adequados de manejo, que, segundo Euclides et al. (1999), é o grande responsável pela expressão do potencial produtivo da forragem. Vale ressaltar que o consumo só será controlado pelo valor nutritivo se a quantidade e a qualidade da forragem disponível forem limitantes (Paulino et al., 2001).

Uma vez que qualquer decréscimo no consumo voluntário tem efeito negativo sobre a eficiência de produção, o entendimento dos fatores que restringem o consumo de forragem pode auxiliar no estabelecimento de manejos que permitam superar essas limitações e melhorar a utilização das pastagens.

Segundo van Soest (1994), o consumo de matéria seca pode estar relacionado com quantidades de fibra e nutrientes digestíveis totais (NDT) presentes na dieta animal, juntamente com fatores associativos dos alimentos nela presentes (Nutrient..., 2001). O efeito associativo dos alimentos que compõem a dieta, possivelmente, interfere no valor dos NDT, que tradicionalmente são usados na avaliação energética dos alimentos e, conseqüentemente, nas diversas formas utilizadas para expressar o valor energético dos alimentos.

No NRC (Nutrient..., 2001), propõe-se uma aproximação aditiva com base na composição dos alimentos que estão sendo utilizados, para se calcular os NDT, que, para mantença, são calculados utilizando as frações verdadeiramente digestíveis dos carboidratos não-fibrosos, da proteína bruta, do extrato etéreo e da fibra em detergente neutro, presentes em cada alimento.

Dessa forma, objetivou-se estimar o valor energético do capim-elefante (Pennisetum purpureum, Schum cv. Napier) e do capimmombaça (Panicum maximum, Jacq cv. Mombaça) e simular parâmetros do desempenho produtivo de novilhas manejadas nessas pastagens.

\section{MATERIAL E MÉTODOS}

O experimento foi realizado no município de Campos dos Goytacazes, RJ. O clima do local, de acordo com a classificação de Köppen, é Aw tropical quente e úmido (Ometto, 1981). A precipitação pluviométrica anual média é de $1060 \mathrm{~mm}$, e a umidade relativa média de $79 \%$.

O experimento foi realizado em dois sistemas de pastejo rotacionado, com a utilização de 15 piquetes de capim-elefante (Pennisetum purpureum, Schum cv. Napier) e 13 piquetes de capim-mombaça (Panicum maximum, Jacq cv. Mombaça), com períodos de ocupação de três dias e descanso de 42 e 36 dias, respectivamente. Para ambas as forrageiras, os piquetes apresentavam área de $600 \mathrm{~m}^{2}$.

Utilizaram-se quatro novilhas mestiças HolandêsZebu, com idade inicial média de 13 meses e peso vivo médio de $240 \mathrm{~kg}$, mantidas exclusivamente em pasto. Foram realizadas pesagens em jejum a cada 28 dias, totalizando seis períodos de avaliação do desempenho animal. O peso vivo e os ganhos diários médios dos animais são apresentados na Tab. 1.

Tabela 1. Ganhos médios diários (GMD - kg/dia) e peso vivo médio (PVM - kg) dos animais em função das gramíneas avaliadas

\begin{tabular}{ccccccc}
\hline \multirow{2}{*}{ Item } & \multicolumn{2}{c}{ Capim-elefante } & & \multicolumn{2}{c}{ Capim-mombaça } \\
\cline { 2 - 3 } \cline { 6 - 7 } & Média & EPM & & Média & EPM \\
\hline GMD & 0,649 & 0,102 & & 0,590 & 0,070 \\
PVM & 292,3 & 14,6 & & 282,2 & 13,7 \\
\hline
\end{tabular}

$\mathrm{EPM}=$ erro-padrão da média.

As áreas de pastagem receberam calagem (calcário dolomítico) conforme os resultados de análises de solo para elevar a saturação de base para o nível de $60 \%$, realizando-se gradagem para incorporação do corretivo ao solo. Quanto à adubação, na formação das pastagens foi utilizado superfosfato simples, para elevar o teor de fósforo para $20 \mathrm{mg} / \mathrm{dm}^{3}$, e adubação de cobertura com $150 \mathrm{~kg} / \mathrm{ha}$ de $\mathrm{N}$, na forma de sulfato de amônio e cloreto de potássio suficiente para elevar o teor de potássio para $130 \mathrm{mg} / \mathrm{dm}^{3}$.

As forragens foram avaliadas qualitativamente por intermédio de amostras de extrusa esofágica (EXT) 
colhidas entre os meses de junho e dezembro de 2002, totalizando quatro ciclos completos de pastejo para ambas as forrageiras.

As colheitas foram realizadas seqüencialmente em cada piquete ocupado, alternando-se o momento da amostragem, de forma que a cada grupo de três piquetes pastejados se obtivessem amostras referentes ao terceiro, segundo e primeiro dias de ocupação. As colheitas de extrusa esofágica foram realizadas em dois novilhos mestiços HolandêsZebu, com média de $420 \mathrm{~kg}$ de peso vivo, fistulados no esôfago, utilizando-se um animal por forrageira, escolhido ao acaso antes de cada colheita. Os animais foram manejados em piquetes anexos aos sistemas de produção para adaptação à dieta e às atividades de pastejo.

$\mathrm{Na}$ noite anterior a cada colheita, os animais foram submetidos a jejum por aproximadamente 12 horas, buscando-se evitar a contaminação das amostras com conteúdo ruminal por regurgitação no momento da coleta (Holecheck et al., 1982). $\mathrm{Na}$ manhã seguinte, os animais foram conduzidos até a área experimental para abertura das cânulas e colocação das bolsas coletoras, confeccionadas em lona impermeável e com fundo telado, para a colheita de extrusa esofágica. $\mathrm{O}$ período de pastejo foi de aproximadamente 40 minutos, após o que se procedeu a limpeza das fistulas e recolocação das tampas e à recondução dos animais ao piquete anexo.

As amostras de EXT foram colocadas em sacos plásticos identificados e armazenadas em congelador a $-15^{\circ} \mathrm{C}$, para posterior análises laboratoriais.

Foram determinados os teores de matéria seca (MS), cinzas $(\mathrm{C})$, proteína bruta $(\mathrm{PB})$ e extrato etéreo (EE), segundo técnicas descritas por Silva (1990), e de fibra em detergente neutro corrigida para cinza e proteína $\left(\mathrm{FDN}_{\mathrm{CP}}\right)$ e fibra em detergente ácido (FDA), conforme as padronizações descritas por Sniffen et al. (1992). A composição químico-bromatológica das extrusas esofágicas são mostradas na Tab. 2.

As estimativas do conteúdo de nutrientes verdadeiramente digestíveis $(\mathrm{dv})$ e de nutrientes digestíveis totais (NDT) da forragem foram obtidas por intermédio da avaliação da composição químico-bromatológica média das extrusas esofágicas em cada período experimental, por meio das equações do NRC (Nutrient..., 2001):

$$
\begin{aligned}
& C N F d v=0,98(100-[(F D N-P B I D N)+P B+(E E-1)+C]) \times F A \\
& P B d v=P B \times \exp [-1,2 \times(P I D A / P B)] \\
& F D N d v=0,75 \times(F D N-L) \times\left[1-(L / F D N)^{0.667}\right. \\
& E E d v=E E-1 \\
& N D T(\%)=C N F d v+P B d v+(E E d v \times 2,25)+F D N d v-7
\end{aligned}
$$

em que: $\mathrm{CNF}=$ carboidratos não-fibrosos; FDN = fibra em detergente neutro; PBIDN = proteína bruta insolúvel em detergente neutro; $\mathrm{PB}=$ proteína bruta; $\mathrm{EE}=$ extrato etéreo (Obs.: quando o $\mathrm{EE}<1$, considera-se $\mathrm{EE}=0) ; \mathrm{C}=$ cinzas; $\mathrm{FA}=$ fator de ajuste (no caso de utilização somente de forragem, FA = 1); e PIDA = proteína insolúvel em detergente ácido.

Tabela 2. Médias para a composição químico-bromatológica de amostras de extrusa esofágica em função das gramíneas avaliadas

\begin{tabular}{lcccccc}
\hline & \multicolumn{2}{c}{ Capim-elefante } & & \multicolumn{2}{c}{ Capim-mombaça } \\
\cline { 2 - 3 } \cline { 5 - 6 } & Média & EPM & & Média & EPM \\
\hline Proteína bruta $(\% M S)$ & 11,20 & 0,50 & & 11,81 & 0,27 \\
Extrato etéreo (\%MS) & 1,35 & 0,30 & & 1,33 & 0,18 \\
FDN $(\% M S)$ & 71,11 & 1,33 & & 71,90 & 0,74 \\
FDA (\%MS) & 34,80 & 2,66 & & 38,92 & 1,46 \\
Lignina (\%MS) & 4,39 & 0,12 & & 4,63 & 0,20 \\
NIDA $^{3(\% M S)}$ & 0,15 & 0,02 & & 0,16 & 0,03 \\
Cinzas (\%MS) & 10,28 & 0,70 & & 12,32 & 0,80 \\
\hline
\end{tabular}

EPM = erro-padrão da média. ${ }^{1}$ Teores corrigidos em função da concentração de proteína insolúvel em detergente neutro. ${ }^{2} \mathrm{NIDA}=$ nitrogênio insolúvel em detergente ácido. 
A partir das informações obtidas por intermédio das equações 1 a 5 , procedeu-se à obtenção das estimativas de concentração energética da forragem por meio das equações do NRC (Nutrient..., 2001):

$$
\begin{aligned}
& E D=((4,2 \cdot C N F d v+4,2 \cdot F D N d v+5,6 \cdot P B d v+9,4 \cdot E E d v) / 100)-0,3 \\
& E M=1,01 \cdot E D-0,45 \\
& E L m=1,37 E M-0,138 E M^{2}+0,0105 E M^{3}-1,12 \\
& E L g=1,42 E M-0,174 E M^{2}+0,0122 E M^{3}-1,65
\end{aligned}
$$

em que: $\mathrm{ED}=$ energia digestível $(\mathrm{Mcal} / \mathrm{kg}) ; \mathrm{EM}=$ energia metabolizável (Mcal $/ \mathrm{kg}) ; \mathrm{ELm}$ e ELg = energias líquidas para mantença e produção, respectivamente $(\mathrm{Mcal} / \mathrm{kg})$; e CNFdv, FDNdv, $\mathrm{PBdv}$ e $\mathrm{EEdv}=$ como definidos anteriormente.

Antecipa-se que todas as estimativas de teor de NDT obtidas por meio da equação 5 situaram-se abaixo de $60 \%$. Dessa forma, não se fez correção para o nível de consumo, conferindo similaridade entre teores de ED e EM para mantença ou produção. Os teores de EE observados situaram-se aquém do limite de $3 \%$, a partir do qual fazem-se necessárias correções para os diferentes níveis energéticos (Nutrient..., 2001).

A partir dos teores energéticos da forragem, o consumo voluntário de matéria seca foi estimado segundo a equação do NRC (Nutrient..., 2001):

$$
C M S=P V^{0,75} \cdot\left(\left(0,2435 \cdot E L m-0,0466 \cdot E L m^{2}-0,1128\right) / E L m\right)
$$

em que: $\mathrm{CMS}$ = consumo de matéria seca $(\mathrm{kg} / \mathrm{dia})$; $\mathrm{PV}=$ peso vivo médio dos animais no período experimental; e ELm = como definido anteriormente.

$$
E L m=0,08 \cdot P V^{0,75}+0,0009 \cdot P V+0,002 \cdot P V
$$

A energia líquida de crescimento disponível para o ganho de peso dos animais foi estimada como:

$$
E L g^{\prime}=\left(C M S-\frac{E L m}{[E L m]}\right) \cdot[E L g]
$$

em que: ELg' = energia líquida disponível para o ganho $(\mathrm{Mcal} / \mathrm{dia}) ; \mathrm{CMS}=$ consumo estimado de matéria seca $(\mathrm{kg} / \mathrm{dia}) ;$ ELm = exigência de energia líquida para mantença (Mcal/dia); $[\mathrm{ELm}]=$ concentração de energia líquida da forragem para mantença $(\mathrm{Mcal} / \mathrm{kg})$; e [ELg] = concentração de energia líquida da forragem para ganho (Mcal/kg).

A partir das estimativas obtidas por meio da equação (12), estimou-se o ganho médio diário de peso dos animais como:

$$
G M D=13,91 \cdot\left(E L g^{\prime}\right)^{0,9116} \cdot \text { PVJeq }^{-0,6837}
$$

$$
E L g=0,0635 \cdot(0,891 \cdot P V J e q)^{0,75} \cdot(0,956 \cdot G M D)^{1,097}
$$

As estimativas de exigências de energia líquida para manutenção animal foram obtidas por intermédio da equação do NRC (Nutrient..., 2001):

em que: $\mathrm{GMD}=$ ganho médio diário $(\mathrm{kg} / \mathrm{dia})$; PVJeq $=$ peso vivo em jejum equivalente $(\mathrm{kg})$; e ELg' = como definido anteriormente.

Por sua vez, o peso vivo em jejum equivalente aplicado à equação (13) foi estimado pressupondo-se o peso vivo adulto $650 \mathrm{~kg}$ dos animais em jejum por meio da equação:

$$
\text { PVJeq }=(0,96 \cdot P V) \cdot\left(\frac{478}{650}\right)
$$

em que: $\mathrm{PV}=$ peso vivo médio dos animais no período experimental $(\mathrm{kg})$; e PVJeq = como definido anteriormente.

Após o procedimento inicial de validação, realizouse um processo de estimação reverso ao até aqui demonstrado, o qual, além das equações até então descritas, utilizou-se de: 
em que: $\mathrm{ELg}$ = exigências de energia líquida para ganho de peso (Mcal/dia); e PVJeq e GMD = como descritos anteriormente.

Os procedimentos estatísticos para avaliação de valores preditos e observados envolveram medidas descritivas básicas (média e erro-padrão da média)

e plotagem de gráficos de dispersão. Em termos indutivos, a comparação entre valores de ganho médio diário preditos e observados baseou-se no ajustamento de modelo de regressão linear simples entre estes, sendo as estimativas dos parâmetros avaliadas sob as seguintes hipóteses:

$$
\begin{array}{ll}
H_{0}: \beta_{0}=0 & H_{0}: \beta_{1}=1 \\
H_{a}: \beta_{0} \neq 0 & H_{a}: \beta_{1} \neq 1
\end{array}
$$

Sob o caso de não-rejeição de ambas as hipóteses de nulidade, optou-se pela similaridade entre valores preditos e observados $(\alpha=0,05)$.

\section{RESULTADOS E DISCUSSÃO}

Os teores médios de energia na forragem, os consumos de matéria seca e os ganhos médios diários estimados segundo o sistema NRC (Nutrient..., 2001), em função das diferentes forrageiras, estão expressos na Tab. 3. Na Fig. 1, representa-se o comportamento descritivo para a relação entre valores preditos e observados para a variável ganho médio diário.

Tabela 3. Médias para a concentração energética, consumo voluntário de matéria seca e ganho médio diário preditos segundo o sistema NRC, em função das diferentes gramíneas avaliadas

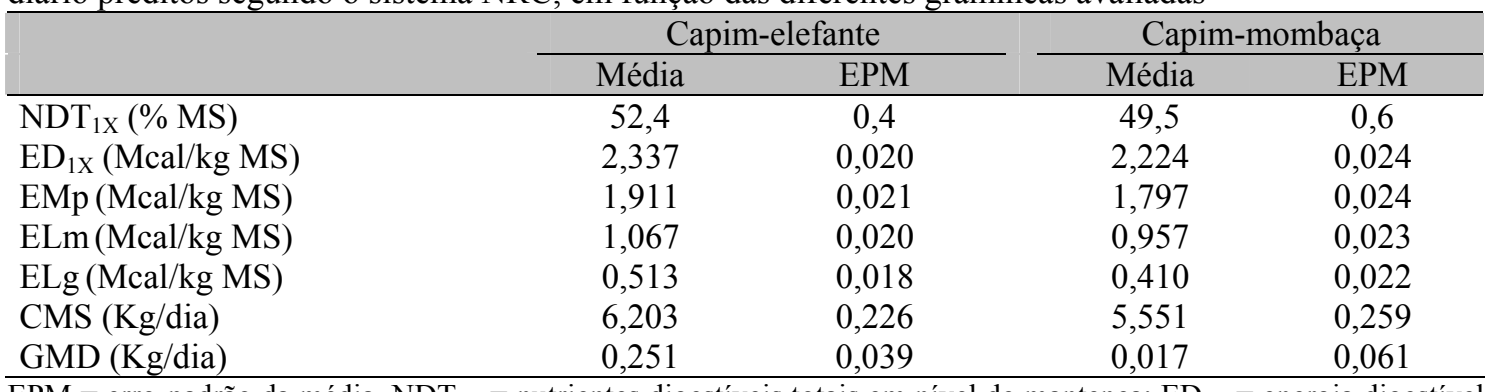

$\mathrm{EPM}=$ erro-padrão da média. $\mathrm{NDT}_{1 \mathrm{X}}=$ nutrientes digestíveis totais em nível de mantença; $\mathrm{ED}_{1 \mathrm{X}}=$ energia digestível em nível de mantença; EMp = energia metabolizável em nível de produção; ELm = energia líquida para mantença; $\mathrm{ELg}$ = energia líquida para ganho de peso; $\mathrm{CMS}$ = consumo voluntário de matéria seca; GMD = ganho médio diário.

A partir da avaliação da relação entre os valores preditos e observados $(\hat{Y}=0,1199+0,0231 \mathrm{X})$ (Fig. 1), apesar da não-rejeição da hipótese de nulidade previamente estabelecida para o parâmetro intercepto $(\mathrm{P}>0,05)$, concluiu-se pela rejeição da hipótese de nulidade associada ao coeficiente de inclinação da relação entre essas variáveis $(\mathrm{P}<0,01)$, o que denota, sumariamente, ausência de equivalência entre valores observados e preditos pelo sistema NRC (Nutrient..., 2001).

A avaliação da dispersão dos pontos no diagrama representado na Fig. 1 permite inferir que o sistema NRC subestimou ganho diário dos animais. $\mathrm{O}$ esquema de dispersão exibido denota relativa ausência de padrão associativo entre os valores preditos e observados. Essa observação é suportada pela não significância observada sobre o coeficiente de correlação linear de Pearson entre essas variáveis $(\mathrm{r}=0,0283 ; \mathrm{P}>0,05)$.
Desse modo, e de maneira simplificada, pode-se afirmar que as estimativas de ganho obtidas segundo o sistema NRC representam o produto entre as estimativas da concentração energética na forragem e do consumo voluntário de matéria seca, pressupondo-se não haver limitações quanto à energia e nem associadas aos nutrientes dos alimentos.

Nesse sentido, partindo do pressuposto de que as estimativas de concentração energética obtidas segundo o sistema NRC não são viciadas, estabeleceu-se um procedimento reverso de simulação, no qual, partindo das estimativas de exigências energéticas para os níveis observados de produção animal, produziram-se valores esperados de consumo voluntário de matéria seca. A relação de tais valores com aqueles inicialmente preditos pela equação (10) é apresentada na Fig. 2. 


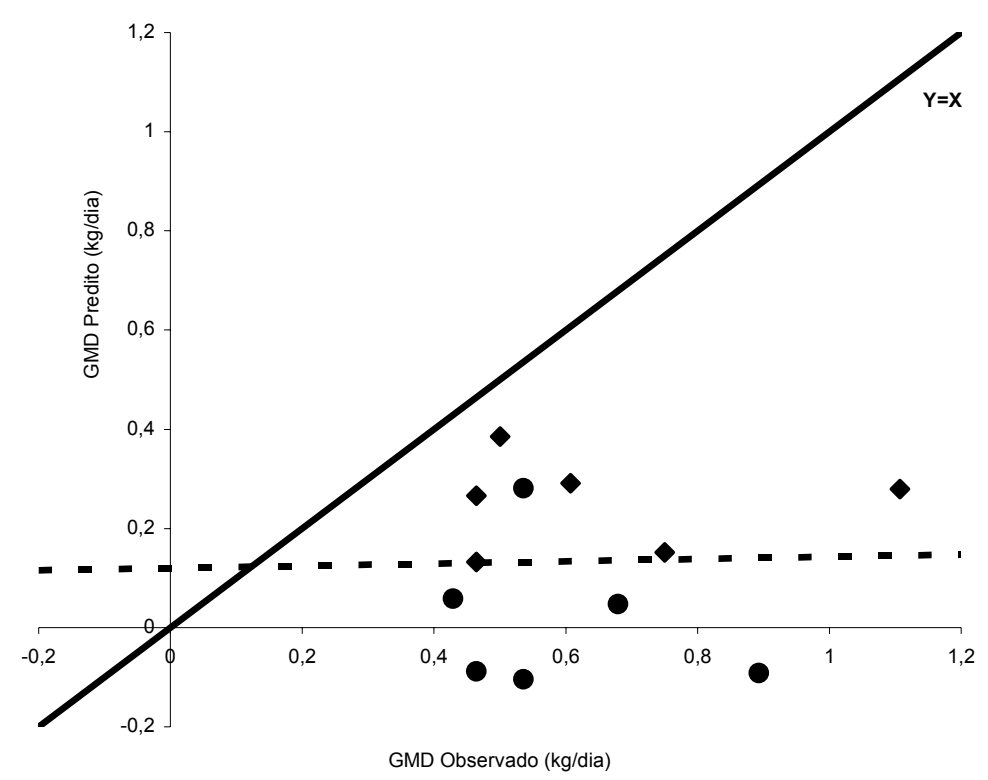

Figura 1. Comportamento descritivo entre valores de ganho médio diário (GMD) observados e preditos por meio do sistema NRC (a linha tracejada corresponde à reta de quadrados mínimos; • = capimelefante; $\bullet$ capim-mombaça).

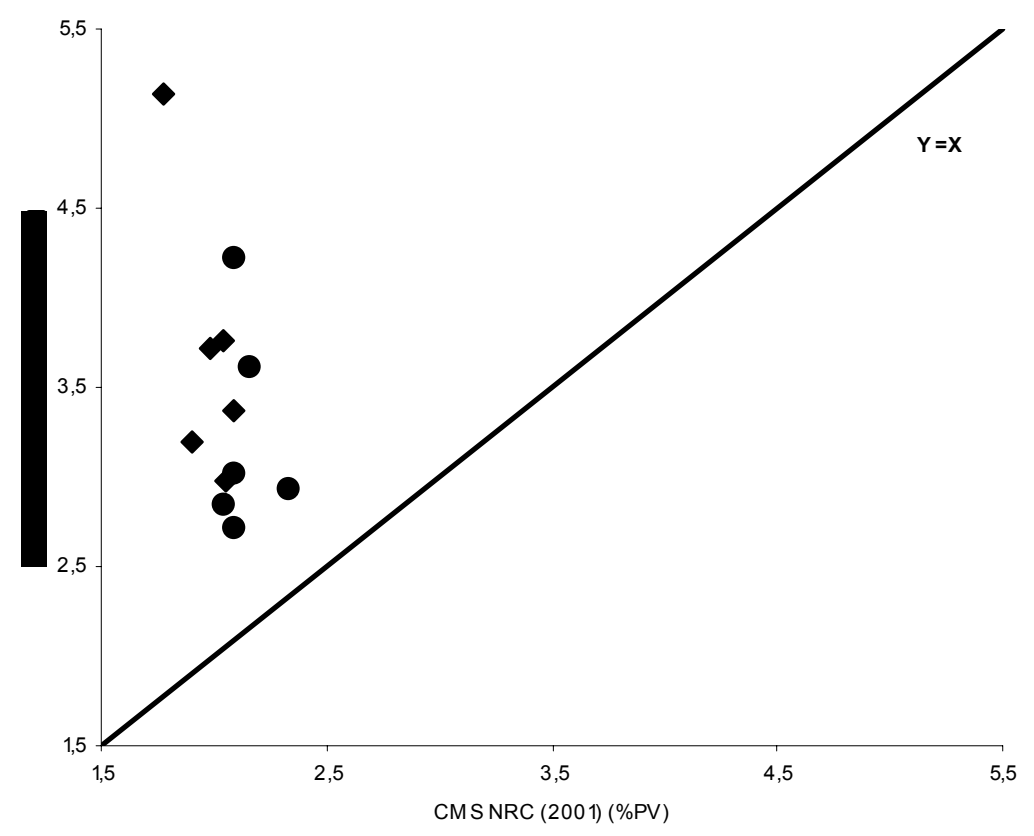

Figura 2. Comportamento descritivo entre valores de consumo voluntário de matéria seca (CMS - \% do peso vivo) estimados segundo o sistema NRC e a partir da relação entre exigência e concentração energética na forragem $(\bullet=$ capim-elefante; $\bullet=$ capim-mombaça $)$. 
A avaliação do padrão de dispersão entre consumos preditos pelo sistema NRC (Nutrient..., 2001) e os esperados para atender aos níveis de produção observados (Fig. 2) indica que os critérios adotados para estimar o consumo voluntário nesse sistema nutricional podem constituir possível entrave à sua correta aplicação em sistemas de alimentação em pastejo.

Procedimentos de validação previamente conduzidos sobre a equação (10) (Nutrient..., 1996) indicaram que esta leva à subestimação do consumo voluntário de animais em crescimento e terminação manejados exclusivamente em pasto, o que confirma o comportamento apresentado na Fig. 2 e implica, conseqüentemente, subestimação da ingestão diária de energia. Segundo recomendações do NRC (Nutrient..., 1996), tal equação deveria ser empregada apenas como indicativo inicial do consumo voluntário dos animais, devendo-se associar informações da situação específica de trabalho para que se obtenham estimativas mais acuradas.

Recentes investigações realizadas no Brasil (Rocha Jr. Et al., 2003; Detman et al., 2004) verificaram subestimação da digestibilidade da FDN por meio das equações propostas pelo NRC (Nutrient..., 2001). Sendo a digestibilidade da FDN integrante do processo de composição da estimativa do teor de
NDT, associa-se, portanto, possível quadro de subestimação do teor energético da forragem.

Detmann et al. (2004), ao avaliarem as estimativas de degradação potencial da FDN por intermédio da equação proposta por Conrad et al. (1984), a qual foi posteriormente incorporada para construção da equação (3), verificaram subestimação da degradação potencial da FDN e sugeriram a substituição do expoente 0,667 pelo fator empírico de correção 0,85, o qual, segundo esses autores, poderia minimizar a ocorrência desse comportamento viesado.

Assim, na Tab. 4, são reapresentadas a concentração de energia, o consumo de matéria seca e o ganho médio diário estimados por intermédio do sistema NRC (Nutrient..., 2001), adotando-se, no entanto, o fator empírico de correção sugerido por Detmann et al. (2004).

Segundo o comportamento de dispersão observado na Fig. 3, a incorporação do fator empírico de correção sugerido por Detmann et al. (2004) elevou, substancialmente, as estimativas de concentração energética na forragem e aproximou essas estimativas de ganho daquelas observadas in vivo (Tab. 1).

Tabela 4. Médias para a concentração energética, consumo voluntário de matéria seca e ganho médio diário preditos segundo o sistema NRC com fator empírico de correção $(0,85)$ em função das diferentes gramíneas avaliadas

\begin{tabular}{lccccc} 
& \multicolumn{2}{c}{ Capim-elefante } & & \multicolumn{2}{c}{ Capim-mombaça } \\
\cline { 2 - 3 } \cline { 5 - 6 } & Média & EPM & & Média & EPM \\
\hline NDT $_{1 \times}(\%$ MS) & 55,52 & 0,41 & & 52,74 & 1,41 \\
ED $_{1 \mathrm{n}}(\mathrm{Mcal} / \mathrm{kg} \mathrm{MS})$ & 2,468 & 0,020 & & 2,358 & 0,056 \\
EMp (Mcal/kg MS) & 2,043 & 0,056 & & 1,932 & 0,056 \\
ELm (Mcal/kg MS) & 1,192 & 0,019 & & 1,087 & 0,053 \\
ELg (Mcal/kg MS) & 0,629 & 0,017 & & 0,532 & 0,053 \\
CMS (Kg/dia) & 6,581 & 0,243 & & 6,116 & 0,621 \\
GMD (Kg/dia) & 0,486 & 0,040 & & 0,267 & 0,146 \\
\hline
\end{tabular}

$\mathrm{EPM}=$ erro-padrão da média. $\mathrm{NDT}_{1 \mathrm{X}}=$ nutrientes digestíveis totais em nível de mantença; $\mathrm{ED}_{1 \mathrm{X}}=$ energia digestível em nível de mantença; EMp = energia metabolizável em nível de produção; ELm = energia líquida para mantença; ELg = energia líquida para ganho de peso; $\mathrm{CMS}$ = consumo voluntário de matéria seca; GMD = ganho médio diário.

Costa et al. (2003), ao avaliarem equações de predição do NRC (Nutrient..., 2001) para valores de energia de alimentos sob condições brasileiras, obtiveram estimativas exatas desses valores. No entanto, esses mesmos autores afirmaram que investigações devem ser realizadas para avaliar especialmente plantas forrageiras tropicais quanto ao seu valor energético sob condições brasileiras.
Tendo em vista que os valores obtidos para o NDT por Costa et al. (2003), para as forrageiras tropicais, estão abaixo dos valores encontrados neste trabalho, subentende-se que houve efeito de interação entre alimentos, o que alterou o valor energético, gerando exatidão nas observações feitas por esses autores. 


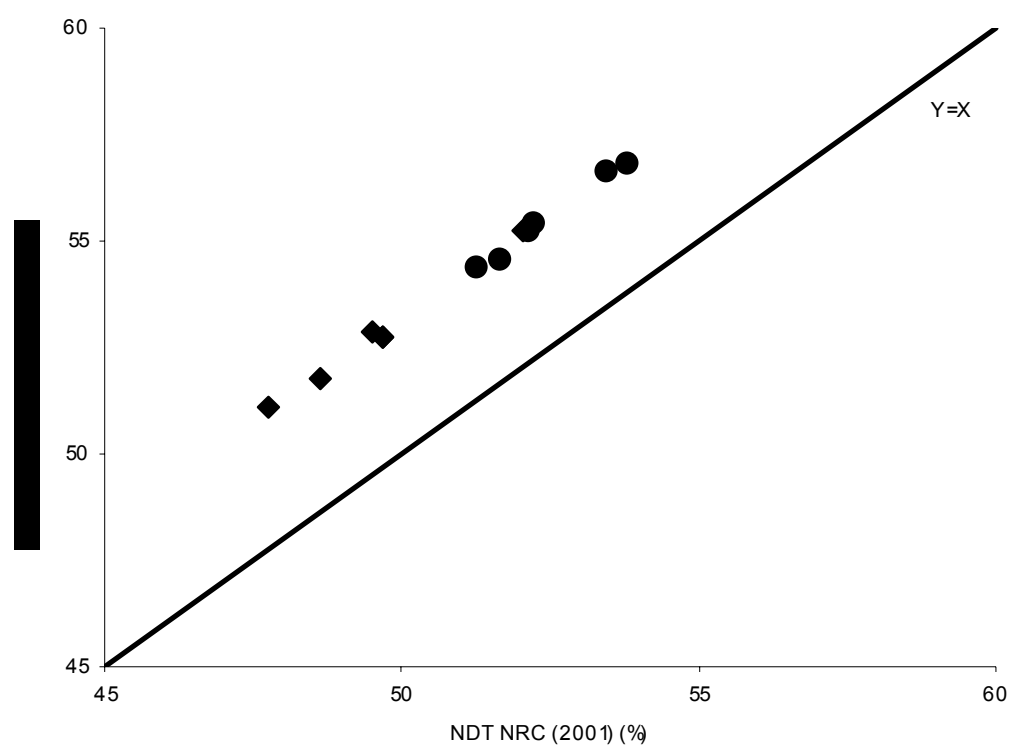

Figura 3. Comportamento descritivo entre teores de nutrientes digestíveis totais (NDT) na forragem (\% da matéria seca) estimados por intermédio do sistema NRC sem e com a inclusão do fator empírico de correção $(\bullet=$ capim-elefante; $\bullet$ capim-mombaça $)$.

Valadares Filho et al., (2002) encontraram 52,9\% de NDT para o capim-elefante, ao compilarem dados para tabelas de alimentos para bovinos. Esse valor é próximo aos verificados no presente trabalho.

Entretanto, os novos resultados parecem assumir proporções mais próximas das estimativas obtidas diretamente com animais. Tal afirmativa suporta-se na similaridade entre as novas estimativas (Tab. 4) e aquelas expostas nas compilações apresentadas pelo NRC (Nutrient..., 1988), em que valores de 55\% de NDT foram relatados para o capim-elefante. Tal comparação indicaria um quadro de subestimação da concentração energética em forragens tropicais por meio do sistema NRC (Nutrient..., 2001). O comportamento observado com a adoção do fator de correção proposto por Detmann et al. (2004) sugere, embora ainda de forma incipiente, que alterações na estrutura das equações permitem aplicá-las em condições tropicais.

\section{CONCLUSÃO}

As equações que estimam o consumo voluntário de matéria seca em função da disponibilidade energética de cada forragem propostas pelo NRC diferiram entre valores preditos e observados, subestimando a energia disponível de alimentos volumosos tropicais, possivelmente pela subestimação da FDN.

\section{AGRADECIMENTOS}

A Felipe Nogueira Domingues e Renata Cogo Clipes pela colaboração a este trabalho.

\section{REFERÊNCIAS BIBLIOGRÁFICAS}

CONRAD, H.R.; WEISS, W.P.; ODWONGO, W.O. et al. Estimating net energy lactation from components of cell soluble and cell walls. $J$. Dairy Sci., v.67, p.427-436. 1984.

COSTA, M.A.L.; VALADARES FILHO, S.C.; PAULINO, P.V.R. et al. Validation of NRC (2001) equations for predicting the energy value of feeds in the Brazilian conditions. In: REUNIÃO DA ASSOCIAÇÃO LATINO AMERICANA DE PRODUÇÃO ANIMAL 18., Porto Alegre. Anais... Porto Alegre, RS, 2003.

DETMANN, E.; ZERVOUDAKIS, J.T.; CABRAL, L.S et al. Validação de equações preditivas da fração indigestível da fibra em detergente neutro em gramíneas tropicais. Rev. Bras. Zootec., v.33, p.1866-1875, 2004. 
EUCLIDES, V.P.B.; THIAGO, L.R.L.S.; MACEDO, M.C.M. et al. Consumo voluntário de três cultivares de Panicum maximum sob pastejo. Rev. Bras. Zootec., v.28, p.1177-1185, 1999.

HOLECHECK, J.L.; VAVRA, M.; PIEPER, R.D. Methods for determining the nutritive quality of range ruminant diets: A Review. $J$. Anim. Sci., v.54. p.363-375, 1982.

NUTRIENT requeriments of beef cattle. 6.ed. Washington, DC: NRC, 1988, 157p.

NUTRIENT requeriments of beef cattle. 7.ed. Washington, DC: NRC, 1996, 242p.

NUTRIENT requeriments of dairy cattle. 8.ed. Washington, DC: NRC, 2001, 456p.

OMETTO, J. C. Bioclimatologia vegetal. São Paulo: Agronômica Ceres, 1981. 440p.

PAULINO, M.F; DETMANN, E.; ZERVOUDAKIS, J. Suplementos múltiplos para recria e engorda de bovinos em pastejo. In: SIMPÓSIO DE PRODUÇÃO DE GADO DE
CORTE, 2., 2001, Viçosa, Anais... Viçosa: SINCORTE, 2001. P.187.

ROCHA JÚNIOR, V.R.; VALADARES FILHO, S.C.; BORGES, A.M. et al. Estimativa do valor energético dos alimentos e validação das equações propostas pelo NRC (2003). Rev. Bras. Zootec., v.32, p.480-490. 2003.

SILVA, D.J. Análises de Alimentos: métodos químicos e biológicos. 2 ed. Viçosa: UFV, 1990. $165 \mathrm{p}$.

SNIFFEN. C.J.; O' CONNOR, J.D.; VAN SOEST, P.J. et al. A net carbohydrate and protein system for evaluating cattle diets: II. Carbohydrate and protein availability. J. Anim. Sci., v.70, p.3562-3577, 1992.

VALADARES FILHO, S.C.; ROCHA JÚNIOR, V.R.; CAPPELLE, E.R. Tabelas brasileiras de composição de alimentos para bovinos. Viçosa: UFV, 2002. 297p.

VAN SOEST, P. J. Nutritional ecology of the ruminant. Ithaca: Cornell University, 1994. 476p. 